\title{
Conservador nos costumes e liberal na economia: liberdade, igualdade e democracia em Burke, Oakeshott e Hayek
}

\author{
Osmir Dombrowski ${ }^{1}$ \\ https://orcid.org/0000-0002-7043-1880 \\ ${ }^{1}$ Universidade Estadual do Oeste do Paraná, Programa de Pós-Graduação em Serviço Social, Toledo, PR, Brasil
}

Conservador nos costumes e liberal na economia: liberdade, igualdade e democracia em Burke, Oakeshott e Hayek

Resumo: Baseado na análise dos textos seminais: Reflexões sobre a Revolução em França, de Edmund Burke; Ser Conservador, de Michael Oakeshott e Por que não sou Conservador, de Friedrich A. Hayek, este ensaio apresenta ao leitor os princípios fundamentais do conservadorismo moderno originalmente articulado em oposição ao liberalismo, ao mesmo tempo em que expõe criticamente os elementos teóricos que permitem sustentar a contraditória aliança política condensada na expressão conservador nos costumes e liberal na economia.

Palavras-chave: Conservadorismo. Liberalismo. Burke. Oakeshott. Hayek.

Conservative in customs and liberal in economics: freedom, equality and democracy in Burke, Oakeshott and Hayek

Abstract: Based on the analysis of the seminal texts Reflections on the Revolution in France, by Edmund Burke; On Being Conservative, by Michael Oakeshott; and Why I Am Not Conservative, by Friedrich A. Hayek, this essay presents the fundamental principles of modern conservatism originally articulated against liberalism, while exposing the theoretical elements that support the contradictory political alliance condensed into the phrase conservative in customs and liberal in economics.

Keywords: Conservatism. Liberalism. Burke. Oakeshott. Hayek.

Recebido em 19.09.2019. Aprovado em 11.02.2020. Revisado em 28.02.2020.

(C) O(s) Autor(es). 2020 Acesso Aberto Esta obra está licenciada sob os termos da Licença Creative Commons Atribuição-NãoComercial 4.0 Internacional (https://creativecommons.org/licenses/by-nc/4.0/deed.pt_BR), que permite copiar, distribuir e reproduzir em qualquer meio, bem como adaptar, transformar e criar a partir deste material, desde que para fins não comerciais e que você forneça o devido crédito aos autores e a fonte, insira um link para a Licença Creative Commons e indique se mudanças foram feitas. 


\section{Introdução}

Nos últimos tempos, tem sido muito frequente, sobretudo na imprensa, o uso da expressão liberal na economia e conservador nos costumes, em alusão a uma posição política que une elementos do conservadorismo e do liberalismo. Do ponto de vista teórico, entretanto, a justaposição dos termos conservador e liberal é algo que requer alguma explicação. Apesar da retórica anticomunista - ou antipetista - adotada por divulgadores de ambas matrizes ideológicas, são imensas as diferenças que as separam.

O conservadorismo surgiu na passagem do século XVIII para o XIX como crítica à Revolução Francesa, seus pressupostos teóricos filosóficos e seus desdobramentos político-institucionais, ou seja, trata-se de uma ideologia que se manifestou historicamente como consequência direta do sucesso do liberalismo. Conservadorismo e liberalismo são, portanto, duas correntes de pensamento que estão historicamente ligadas, porém, de modo dialético, uma como negação da outra.

O ensaio aqui apresentado faz uma breve incursão no interior dessas duas correntes de pensamento e, ao mesmo tempo em que apresenta ao leitor seus princípios fundamentais, busca encontrar em cada uma delas, um ponto de apoio suficientemente firme para sustentar a propalada aliança entre conservadores e liberais, apesar das contradições que ela suscita.

Como é amplo o consenso entre estudiosos ${ }^{1}$ de que as Reflexões sobre a Revolução em França (1790) constituem o marco inicial do moderno pensamento conservador, o presente ensaio tem na célebre obra de Edmund Burke (1982) o seu ponto de partida. Em seguida, faz-se uma digressão sobre a atualização do conservadorismo efetuada pelo filósofo inglês Michael Oakeshott (2016), o mais original pensador conservador do século XX, condensada no ensaio Ser Conservador de 1956. A contraposição do pensamento conservador com o liberalismo é sensivelmente facilitada pelo ensaio Por Que Não Sou Conservador, escrito na mesma época pelo influente pensador liberal Friedrich August Hayek (2006) e publicado como posfácio de Os Fundamentos da Liberdade em 1959. Por fim, a análise dessas três obras seminais é concluída com algumas reflexões sobre a relação de ambas as correntes teóricas com o movimento democrático.

\section{Burke - origens do conservadorismo}

Foi no calor dos fatos que Edmund Burke escreveu suas Reflexões sobre a Revolução em Fran$c ̧ a^{2}$. Nelas, o polemista britânico se mostra extremamente preocupado com os rumos que a revolução tomava na França e com a influência que ela exercia sobre o restante da Europa, principalmente, sobre a Inglaterra. Em primeiro lugar, Burke (1982) condena inapelavelmente o fato de que os revolucionários se mostravam mais dispostos a se orientar pela razão abstrata do que pela experiência acumulada ao longo dos séculos. Com isso, evidencia-se o grande apreço que o cavalheiro inglês nutria pela tradição, ao lado da profunda desconfiança, desde então compartilhada por todos os conservadores, em relação ao racionalismo iluminista e à crença na capacidade humana de estabelecer relações sociais fundadas na razão e não baseadas em dogmas e preconceitos.

Para Burke, negar hábitos e costumes estabelecidos e começar uma organização política a partir de abstrações não era apenas um equívoco, mas uma opção que só poderia gerar "calamidades" (BURKE, 1982, p. 73). Em sua avaliação, o caminho natural e seguro, estava sendo abandonado pelos franceses em detrimento de outro, artificial, criado por homens que se colocavam, dessa maneira, no lugar do próprio criador, de onde ele deduz a inevitabilidade de um efeito perverso, como uma espécie de castigo dos céus ${ }^{3}$. Deve-se registrar aqui que o natural nesse raciocínio equivale à criação divina, o que confere à tradição abraçada pelo pensamento conservador um fundamento religioso praticamente inevitável que, fatalmente, haveria de se chocar com a laicidade sustentada pelo iluminismo e institucionalizada pela Revolução Francesa.

Os franceses haviam criado ao longo de sua história um conjunto de instituições políticas que, para Burke, poderiam levá-los a superar a crise em paz e segurança e que, portanto, não deveriam ser simplesmente descartadas naquele momento. Mesmo os Estados Gerais, uma instituição tradicional que havia servido aos interesses da nação por séculos, eram, para ele, um bom ponto de partida. Contudo, os revolucionários, agindo “[...] como se pudessem refazer tudo a partir do nada" (BURKE, 1982, p. 71), haviam preferido o caminho da Assembleia Nacional, em que o Terceiro Estado igualado numericamente às outras ordens, emergia soberano, apagando as distinções sociais. E o Terceiro Estado, para Burke, nada tinha que pudesse oferecer à nação.

Tomando apenas e tão somente a lista de nomes e as ocupações dos membros da Assembleia e constatando nela a presença de "[...] profissionais inferiores, ignorantes, mecânicos, [...] obscuros advogados de província [...]" e "[...] todo o bando de chicaneiros municipais [...]", Burke se sente capaz de emitir um juízo profético: "Assim que vi a lista, vi distintamente, e quase como se passou, tudo aquilo que se 
seguiria." (BURKE, 1982, pp.75-76). Para ele, o Terceiro Estado era tão incapaz politicamente que até mesmo o caos que se estabeleceu em consequência de sua soberania só poderia ser atribuído a membros decaídos das ordens superiores, notadamente à representação do clero, em que "[...] figurava um grande número de vigários de vila.", que "[...] não tinham a menor ideia do que fosse um Estado [...]", e a traidores oriundos da própria nobreza, que "[...] sacrificaram os interesses de sua classe, em favor de vantagens pessoais." (BURKE, 1982, p. 79). Com esse argumento, Burke contorna uma enorme falha em seu laudo acusatório. Afinal, seria no mínimo contraditório imputar aos obscuros e ignorantes membros do Terceiro Estado, chicaneiros e vigários de vila, a autoria de uma obra com a dimensão da revolução em curso, capaz de submeter a grandiosa elite francesa forjada pela experiência de séculos nos caminhos da tradição, e de estender sua influência sobre toda a Europa aristocrática, logrando obter simpatizantes e seguidores, inclusive entre seus pares no parlamento inglês.

Aplicar uma racionalidade aritmética às coisas da política, na opinião de Burke, era um grande equívoco. Afirmar que "[...] vinte e quatro milhões devem prevalecer sobre duzentos mil", diz ele, "é ridículo". (BURKE, 1982, p. 83). Trata-se, para ele, de um cálculo abstrato que desconsidera aquilo que verdadeiramente importa nos governos; os atributos pessoais dos governantes: a honra, a virtude e a sabedoria. $\mathrm{E}$ as eleições não podem conferir aqueles atributos a quem já não os tenha. Os "[...] metafísicos e alquimistas de legislação [...]" ao acabar com as distinções e os privilégios de classe, "reduziram os homens à mera condição de números em uma conta, sem conceder-lhes a importância decorrente dos lugares que ocupam." (BURKE, 1982, p. 178). Para Burke (1982, p. 81), "A ocupação de um cabeleireiro, ou de um operário fabricante de velas - para não falar de muitas outras ocupações servis - não pode ser motivo de honra para pessoa alguma.". De acordo com o célebre polemista, quem exerce profissões como estas não deve ser chamado ao governo de um Estado, e ao chamá-los, o legislador está, "[...] na verdade, colocando-se em guerra civil contra a natureza." (BURKE, 1982, p. 81).

Embora abominasse o raciocínio aritmético dos legisladores franceses que consagravam a igualdade, Burke não se acanhou em usar a aritmética da propriedade como argumento em defesa da desigualdade. Mesmo reconhecendo que todos os homens têm direito a "todas as vantagens" proporcionadas pela vida em sociedade, para ele, "[...] todos os homens têm direitos iguais, mas não às mesmas coisas". (BURKE, 1982, p. 88). Segundo o austero conservador, "Aquele que subscrever cinco shillings em uma sociedade tem direito à renda dos cinco shillings, da mesma forma que aquele que empregar quinhentas libras esterlinas tem direito proporcional à quantia aplicada". (BURKE, 1982, p. 88). A aritmética niveladora para Burke é ridícula, pois termina fundamentando um princípio de representação baseado em uma igualdade abstrata, metafísica. A aritmética dos negócios, porém, é usada para fundamentar a ideia de uma representação desigual, que favorece a propriedade, principalmente, a grande propriedade.

De acordo com o polemista britânico, a desigualdade é a " [...] característica essencial da propriedade [...]" e se desenvolve naturalmente ao longo dos anos pela combinação dos princípios de aquisição e de conservação (BURKE, 1982, p. 83). Para Burke (1982, p.82), a propriedade estará sempre sob ameaça, “[...] a menos que seja desproporcionalmente dominante na representação" dos Estados, pois ela tende a estimular a inveja e a cobiça. No pensamento conservador, portanto, a igualdade aparece como algo artificial, criada por metafísicos e alquimistas de legislação e a desigualdade, como um dado real, com origem na distribuição naturalmente desigual da propriedade e que, como tal, justifica a desigualdade política. Assim, a desigualdade política não apenas é entendida como uma função da desigualdade econômica, mas também é justificada como instrumento necessário para preservá-la; especialmente as grandes propriedades, que "[...] formam uma espécie de proteção natural em volta das propriedades de menor importância [...]” (BURKE, 1982, p. 83).

Na França revolucionária, como forma de garantir a liberdade, a Assembleia Nacional procurava instituir um sistema de representação política repercutindo a ideia iluminista de que a melhor forma de um povo não ser oprimido pelo governo é ele próprio se governar; princípio ao qual Rousseau se referiu em seu Contrato Social com a magistral observação de que uma pessoa é livre quando obedece apenas a si mesmo; não ao "impulso do puro apetite" que é uma forma de escravidão, mas à razão que confere moralidade às suas ações. (ROUSSEAU, 1991, p. 32). Burke, entretanto, novamente invocando a tese da perversidade, alardeava que tudo o que a Assembleia Nacional propunha naquela direção estava, na verdade, seguindo em direção oposta e conduziria fatalmente à perda da liberdade. Ainda que apresentasse longos comentários críticos ao novo arranjo institucional adotado na França e dedicasse a isto um capítulo inteiro de suas Reflexões, o que se destaca em sua argumentação é que a liberdade, cuja perda ele lamentava, é significativamente diferente daquela almejada pelos revolucionários na França.

Enquanto a França revolucionária se aproximava de uma noção de liberdade umbilicalmente ligada à igualdade política, o raciocínio de Burke, consagrando a desigualdade como dado natural, seguia em direção contrária. De acordo com o parlamentar britânico, a Revolução Inglesa de 1688 “[...] foi feita para conservar 
nossas leis e liberdades tradicionais [...]", mas na Declaração dos Direitos que funda o reinado de Guilherme não existe uma só palavra sobre o "[...] "direito de estabelecer um governo para nós mesmos"." (BURKE, 1982, p. 67-68). "[...] da Carta Magna à Declaração de Direitos [...]”, diz ele, a liberdade sempre foi reivindicada na política inglesa como uma "[...] herança, um legado que nós recebemos de nossos antepassados e que deveremos transmitir a nossa posteridade [...]" (BURKE, 1982, p. 69, grifo do autor). Ao considerar a liberdade como uma herança, Burke acredita que "[...] o espírito de liberdade que, por si só, conduz às desordens e aos excessos é temperado por uma respeitosa gravidade." (BURKE, 1982, p. 69-70). E dessa forma, a liberdade "[...] torna-se uma nobre independência; ela traz consigo um aspecto imponente e majestoso; tem sua genealogia e ancestrais ilustres; tem seus sustentáculos e brasão de armas [...]". (BURKE, 1982, p. 70).

Para um insuspeito sociólogo conservador como Nisbet (1987, p. 63), há um inegável elemento de feudalismo na teoria da autoridade de Burke, e "na lei medieval, «liberdade» era antes de mais nada o direito dos grupos corporativos à sua autonomia". Outros conservadores, a exemplo de Joseph de Maistre (1990), afirmarão de modo muito mais enfático que a autoridade tem origem exclusivamente em Deus, que a delega à Igreja, à família e aos governos, cada um em seu domínio específico. Porém, ainda que o argumento de Burke não retornasse diretamente a Deus e sim à tradição, é certo que ele recusava a ideia de soberania popular adotada pelos revolucionários e que defendia a manutenção dos corpos intermediários que compunham a cadeia de autoridade do sistema feudal como necessária para garantir a liberdade.

A liberdade que emerge do pensamento conservador, portanto, não é a ausência de restrição que caracteriza o individualismo liberal ou o direito de se autogovernar que corresponde ao ideal republicano de soberania popular. A liberdade advogada por Burke, que se tornaria paradigmática entre os conservadores, é uma liberdade temperada, moderada pelos costumes, pela tradição e, fundamentalmente, pela ação daqueles corpos que no sistema feudal, por um lado, forneciam uma identidade e davam proteção aos indivíduos que a eles estavam ligados e, por outro, os submetiam às suas regras, leis e padrões morais e monopolizavam toda relação deles com o mundo exterior, de modo que nada, seja material ou espiritual, que não houvesse passado por seu controle chegava a eles e nada emanava deles que não fosse por seu intermédio.

A assertiva burkeana contra a racionalismo aritmético dos iluministas, ao mirar a igualdade e a liberdade, posiciona o pensamento conservador no interior de um debate que ainda consumiria muita tinta e que seria levado adiante por teóricos como Benjamin Constant e Tocqueville. Não obstante, o que efetivamente resta do pensamento de Burke é que sua defesa da desigualdade como condição natural e da liberdade moderada o leva a recusar cabalmente o arranjo institucional criado a partir daqueles pressupostos que serviu de base para o desenvolvimento do Estado liberal e da democracia entre os modernos.

Por acreditar que os homens são igualmente dotados de razão e capazes de discernir entre o bem e o mal, o iluminismo acaba preconizando um ambiente político seguro para que cada um possa expressar livremente suas ideias e faz do livre confronto de opiniões o princípio legitimador das decisões coletivas. Desse modo, no Estado moderno, a legitimidade se encontra ancorada nessa esfera pública de debates que torna possível a formação de consensos mais ou menos amplos e repousa, sobretudo, no conjunto de instituições que permitem o seu funcionamento, notadamente aquelas que são responsáveis pela garantia da livre participação dos cidadãos.

Para Burke (1982, p. 88), porém, o direito de participar do governo não é algo que possa ser atribuído indistintamente a todos: “[...] no que concerne à participação no poder, [...] nego-lhe a faculdade de estar entre os direitos originais do homem na sociedade [...]". Aqui é preciso destacar que quando Burke se refere aos direitos do homem na sociedade, ele se afasta da moderna doutrina dos Direitos Naturais que influenciou fortemente o ordenamento jurídico e político dos Estados Modernos, especialmente a Declaração dos Direitos do Homem e do Cidadão, recém promulgada pela Assembleia Nacional e alvo das suas investidas. Para o autor das Reflexões "[...] os direitos dos homens são incompatíveis com a ideia de sociedade" (BURKE, 1982, p. 90), porque não é possível contemplar toda a sociedade a partir de um único ponto de vista e, dessa forma, "Os direitos que esses teóricos da Constituição pretendem obter são todos absolutos: em que pese sua verdade metafísica, são moral e politicamente falsos." (BURKE, 1982, p. 91).

A moderna doutrina dos Direitos Naturais está baseada na ideia de que existe um conjunto de direitos que pode ser acessado pela razão e inclui, fundamentalmente, o direito à vida, à liberdade e aos meios necessários para a sua manutenção. De acordo com essa doutrina, os Direitos Naturais não apenas antecedem o direito positivo, cronológica e valorativamente, como o próprio Estado foi criado pela razão humana com a função de preservar e garantir o seu usufruto. Assim, a consagração na forma de leis positivas do direito à liberdade e à proteção da vida, incluindo a integridade física, tal como ocorreu na França revolucionária, é expressão de uma sociedade que encontrou naquela doutrina uma referência moral. E essa certamente foi a maior referência de todos aqueles que lutaram por direitos ao longo dos mais de duzentos anos que nos separam da Revolução Francesa - as mulheres em primeiríssimo lugar, com os exemplos de Olimpe de Gouges e Mary Wollstonecraft, 
contemporâneas de Burke, que no calor da Revolução olhavam para o futuro e não para o passado - e, seja pela atribuição de direitos antigos a novos atores, seja de novos direitos a antigos atores, contribuíram para moldar a moderna noção de cidadania como Marshall (1967) narrou de forma magistral.

Há que se reconhecer a crítica de Marx (1991), para quem o limite da emancipação política do cidadão anunciada pelo Estado Moderno é visível no fato de que ele proclama que todo membro do povo participa da soberania popular em pé de igualdade, mas não impede que a propriedade privada faça valer o seu poderio desigual, pelo contrário, protege-a com todas as suas forças. Como também é preciso concordar com a crítica feminista no entendimento de que a atuação das mulheres deve operar uma transformação radical no espaço público que foi construído por homens a sua imagem e semelhança e, como tal, é um espaço de opressão para as mulheres (FRASER, 2007; YOUNG, 2012). Essas críticas, entretanto, apontam para a construção de uma sociedade nova, em que a igualdade e a liberdade atinjam sua plenitude e deixem de ser um enunciado formal. Burke, por seu lado, apega-se a reminiscências de um passado feudal que se desmancha diante de seus olhos e, em uma tentativa quase quixotesca, quer conservá-lo.

\section{Oakeshott - conservadorismo atualizado}

Em meados do século XX, poucos pareciam acreditar que um retorno a um passado feudal fosse possível ou desejável, à exceção de alguns fanáticos adeptos de seitas medievais saudosas do monopólio católico da moral como a execrável Tradição, Família e Propriedade (TFP) e de outras figuras igualmente deploráveis de mentalidade pré-científica que se orientam pelos astros. Por conta disso, os conservadores se veem obrigados a operar uma atualização de seus postulados, abdicando de qualquer intenção restauracionista, tornando desnecessário ser defensor da ordem monárquica para ser conservador. No ensaio Ser Conservador (On Being Conservative), publicado em 1956, Oakeshott (2016, p. 210) ${ }^{4}$ leva ao extremo essa tarefa: "A bem da verdade, não acho que ele [o conservador] tenha que estar conectado com nenhuma bandeira em particular sobre o universo, sobre o mundo em geral ou sobre a conduta humana". Para o prestigiado ocupante da cátedra de Ciência Política da London School of Economics, ser conservador significa apenas "preferir alguns tipos de condutas e algumas circunstâncias de condições humanas a outras" (OAKESHOTT, 2016, p. 176) e isso não implica a filiação automática a qualquer conjunto sistemático de preceitos políticos.

Em sua atualização, Oakeshott (2016) afasta a ideia de um conservadorismo apegado ao passado. Para ele, o conservador não idolatra "[...] o que meramente jaz no passado.” (OAKESHOTT, 2016, p. 177). Ele reconhece o presente como uma herança e expressa gratidão e reconhecimento por isso, mas "o que importa mesmo é o presente", e não porque este guarda conexões com alguma antiguidade remota ou alguma tradição, mas por sua "familiaridade"; porque estamos "apegados" a ele (OAKESHOTT, 2016, p. 177).

A redefinição de Oakeshott traz algumas implicações. Primeiro, "se o presente for árido" e não oferecer nada que possa ser aproveitado, diz Oakeshott (2016, p. 178), a inclinação ao conservadorismo "será mais fraca ou ausente". Se o presente apresentar muita instabilidade, o conservadorismo "consistirá em uma busca por algo que seja firme e confiável” e, nessa busca, o conservador explorará "o que houver de melhor no passado". (OAKESHOTT, 2016, p. 178). Por fim, se o presente for auspicioso e abundante, o conservadorismo então "se mostrará com toda sua força”. (OAKESHOTT, 2016, p. 178). O próprio Oakeshott (2016, p. 178) conclui - de modo um tanto inadvertido - que o seu conservadorismo "[...] é uma disposição típica de quem acredita ter algo a perder, algo que o tempo o ensinou a amar".

O conservador, para Oakeshott, é alguém que desconfia das mudanças e das inovações. As mudanças, diz ele, vão de encontro ao temperamento conservador e são bem recebidas apenas por “[...] aqueles que não prezam por nada" (OAKESHOTT, 2016, p. 180). Já aqueles que sabem o que possuem não conseguem permanecer indiferentes às mudanças; sentem-nas como ameaça a sua existência, ao seu modo de vida. Da mesma forma, o conservador também vê com muita desconfiança a ideia de inovação, primeiro, porque "toda inovação requer uma mudança" e depois, porque toda inovação envolve um "cálculo de perdas e ganhos" que não pode ser realizado com precisão antes do fim do processo (OAKESHOTT, 2016, p. 184).

A disposição em ser conservador, "fria e crítica quanto à mudança e inovação" (OAKESHOTT, 2016, p. 186), faz com que o homem com esse temperamento não tenha nada de aventureiro, e em todas as circunstâncias seja orientado pela prudência. Em síntese, "seu paradigma o obriga a enxergar dada situação de mudança nos termos da propensão para romper com a familiaridade dos aspectos de seu mundo" (OAKESHOTT, 2016, p. 187).

Ao definir o conservador como alguém que aprendeu a gostar da sua condição de vida e que receia as mudanças e inovações, Oakeshott (2016) tenta evitar que o conservadorismo seja tomado como uma ideologia em oposição a outra, ou outras. Em vez disso, em sua acepção, o conservadorismo se apresenta como uma 
simples disposição; uma propensão que, se não é inerente à natureza humana, é, com toda certeza, diz ele, constituinte da "natureza humana atual" (OAKESHOTT, 2016, p. 189). Com o adjetivo "atual", Oakeshott se refere ao homem moderno que, segundo ele, "[...] durante os últimos cinco séculos mais ou menos," demonstra ter adquirido um apetite insaciável pela mudança e pela inovação, e se mostra tão desapegado de sua identidade que a arrisca "por qualquer coisa" (OAKESHOTT, 2016, p. 189).

Para Oakeshott (2016), o culto à mudança que vigora entre nós torna a disposição conservadora algo desmerecido e o homem que apresenta essa propensão é visto como alguém "[...] que provoca pena como pária e desdém como reacionário." (OAKESHOTT, 2016, p. 192). Entretanto, mesmo nessas circunstâncias, não apenas há ocasiões em que uma disposição conservadora se mantém apropriada, como "[...] há momentos nos quais somos inevitavelmente compelidos a seguir uma direção conservadora" (OAKESHOTT, 2016, p. 193, grifo nosso). Nas relações onde não se busca nenhum benefício, "[...] e que são desfrutadas pelo simples prazer de deleite" (OAKESHOTT, 2016, p. 195), como na amizade, a conduta considerada correta é a conservadora. De uma amizade, assevera o moralista, não se espera recompensas, somente a satisfação e o prazer de poder desfrutá-la, e os amigos, aceitamo-los como eles são, "livre da sanha de mudança e melhora" (OAKESHOTT, 2016, p. 196). A lealdade que mantemos para com os amigos não decorre de interesses ou do cálculo utilitarista, mas apenas da familiaridade e do apego adquirido com o tempo.

E o que vale para a amizade, diz Oakeshott (2016, p. 196), “[...] também vale para outras experiências - como o patriotismo ou a conversação -, cada uma delas exige uma inclinação conservadora para ser desfrutada.". Em sua análise, "[...] a conduta de uma sessão pública, as regras de debate no congresso ou os procedimentos de uma corte de justiça" (OAKESHOTT, 2016, p. 205) também são produtos da experiência obtida ao longo do tempo aos quais os participantes estão familiarizados e que produzem certas expectativas às quais devem corresponder, e caso não estivessem protegidos pela disposição conservadora e fossem submetidos a reformas a toda hora "perderiam seus valores" (OAKESHOTT, 2016, p. 206).

Note-se que Oakeshott (2016), em um primeiro momento, retira o conservadorismo da esfera da política, que abrange a coisa pública, e o desloca para território das coisas privadas, tomando como referência elementos que remetem a sensações e sentimentos como familiaridade, apego, satisfação, prazer, lealdade etc., que não podem ser facilmente reduzidos a cálculos racionais, utilitaristas, de custo e benefício ou perdas e ganhos. É no mundo privado que ele consegue identificar a existência de uma disposição conservadora, percebida como uma propensão constituinte da própria natureza do homem atual. Ao final, quando Oakeshott retorna ao campo das coisas públicas, o conservadorismo aparece não apenas desvinculado de qualquer ideologia ou bandeira, como se impõe sobre a política como uma disposição pela qual somos inevitavelmente compelidos.

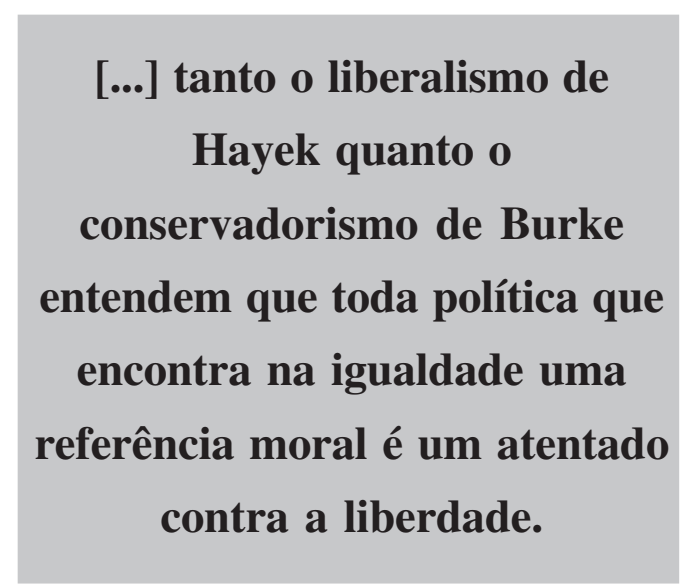

Ocorre que, diferentemente do mundo privado, no espaço público democrático o debate requer que as opiniões sejam de alguma forma acompanhadas por justificativas racionais para que possam ser ponderadas e aceitas ou contestadas. Nesse ponto, é elucidativo compreender por que o conservador vocifera contra tudo que se convencionou chamar de politicamente correto. O que amiúde se diz ser politicamente correto, ou incorreto, corresponde a um juízo feito em bases racionais e comunicado no espaço público, cuja refutação deve ser feita também por meio de argumentos racionais e não fundada em preconceitos, afeições ou preferências que muito dificilmente se colocam como objeto de julgamento e discussão. Incapaz de sustentar um debate em termos racionais, resta o apelo à truculência verbal; ao vitupério e à ignomínia que, com frequência, evolui para violência física.

O conservadorismo atualizado de Oakeshott (2016), portanto, se expressa como uma tentativa de subordinar a política por meio da imposição de determinantes morais supostamente superiores porque são derivados da própria natureza humana atual. Subordinando a política, o conservadorismo pretende impedir que as mudanças aconteçam ou, quando o novo for inevitável, espera mitigar seus efeitos. Isso explica em grande parte o comportamento dos conservadores que, geralmente, se autoidentificam como apolíticos e mesmo quando manifestam publicamente suas opiniões fazem questão de que sejam manifestações sem partido. Explica, também, porque, quando o seu engajamento político se torna inevitável - naquelas conjunturas as quais Oakeshott (2016) se refere como muito instáveis -, o conservador preferirá atuar fora do sistema, contra o sistema, ou como antissistema. 
A disposição conservadora aplicada à política, segundo Oakeshott (2016), precisa ser compreendida a partir da forma como o conservador concebe a atividade específica e limitada de governar uma sociedade. $\mathrm{O}$ teórico inglês entende que a realidade não é produto de nenhum autor em particular, humano ou divino, e não resulta de qualquer determinante singular. A realidade, diz ele, é produto da "capacidade que os seres humanos adquiriram de fazer escolhas por si próprios" (OAKESHOTT, 2016, p. 213) ao longo da história, e é extremamente difícil, senão impossível, prever onde essa capacidade nos levará no futuro. Essa condição de incerteza, segundo Oakeshott (2016), irrita algumas pessoas que se ressentem da falta de um sentido de direção e que sonham em converter esse caos em ordem, instituindo uma maneira diferente, mais gloriosa, para a humanidade viver. Ironizando a atuação política dos militantes progressistas, Oakeshott (2016, p. 215) diz que, para aquelas pessoas, "[...] a política se torna uma reunião de sonhos e a atividade de governar passa a consistir na busca por instrumentos que os traduzam em realidade".

Já os conservadores entendem de modo diferente o ato de governar e de fazer política, e a raiz desse entendimento, diz Oakeshott (2016, p. 216), “está na aceitação da atual condição humana” e no receio diante das mudanças. Para eles, "o ofício de governar não é impor aos outros suas crenças, nem educar ou tutelar ninguém, nem fazê-los melhores e mais felizes de outra maneira”. Governar não é também "[...] liderar ou coordenar suas atividades de forma que nenhum conflito surja;" (OAKESHOTT, 2016, p. 217). Para o teórico do conservadorismo atualizado, governar é "simplesmente garantir que a lei seja cumprida." (OAKESHOTT, 2016, p. 217).

Se o primeiro conservador se levantou contra o liberalismo que emergiu com a Revolução Francesa, o que se pode entrever no estilo laissez-faire de governar e fazer política preconizado por Oakeshott (2016) é que o inimigo contra o qual o conservadorismo se erguia em meados do século XX era outro, embora igualmente insatisfeito com a atual condição humana e ameaçador em sua disposição para reorganizar a sociedade em moldes por ele sonhado. Depois da Segunda Grande Guerra, os conservadores encontravam na União Soviética, com sua economia planificada e relações sociais reguladas impositivamente, um exemplo concreto de onde a política racionalista que eles combatiam poderia levar. Entretanto, tal como Burke havia criticado a Revolução na França de olho na Sociedade da Revolução e outras associações que atuavam em território britânico, Oakeshott também não está olhando apenas para a longínqua Rússia. Por todo o território europeu, o Estado liberal se encontrava submetido a uma grande pressão transformadora decorrente da incorporação ao sistema representativo da imensa maioria formada pelas mulheres e pelos segmentos não proprietários. Depois da derrota do nazifascismo, quando o capitalismo vivia sua era dourada, a ameaça sentida pelos conservadores se apresentava na forma da conquista progressiva dos direitos que davam forma ao Estado de Bem-Estar.

Se para Oakeshott (2016) governar é garantir o cumprimento das leis, para entendê-lo é preciso verificar como ele pensa a relação entre a lei, o governo e a sociedade. Nesse sentido, o filósofo inglês entende que a resolução de conflitos entre pessoas que perseguem livremente interesses diferentes, não é algo fácil de obter. Quando um conflito se estabelece com alguma gravidade, a solução deve vir de fora, por meio de um juiz imparcial e com autoridade superior, porém, ela não pode ser imposta, como algo decidido arbitrariamente por um terceiro com base unicamente em suas crenças ou em seu humor. Para Oakeshott (2016), quanto mais grave for uma dissensão, mais necessária é a existência de um ritual para a sua solução, com regras e procedimentos que sejam familiares e aceitos por todos. O tutor desse ritual é o que Oakeshott (2016, p. 220) chama de governo, e as leis são as regras que o ritual impõe.

De acordo com Oakeshott (2016), nenhum governo consegue se sustentar se não despertar a lealdade de seus súditos, e, para que isso ocorra, a familiaridade com as regras oferecidas por ele é fundamental. Por isso, as modificações nas regras, mesmo quando necessárias para dar conta de inovações, "devem sempre refletir, e nunca impor, uma mudança nas atividades e nas crenças daqueles que as professam" (OAKESHOTT, 2016, 224). Dessa forma, Oakeshott (2016, p. 224-225) conclui que o conservador jamais aceitará mudanças nas leis "feitas para atingir situações hipotéticas" de "bem comum" ou de "justiça social", como também não aceitará governantes que requerem poderes para promover tais mudanças.

É redundante em Oakeshott o temor de que o governo seja usado como instrumento para promover transformações. O mais importante em seu pensamento, porém, é que o governo imaginado por ele, garantindo apenas o cumprimento das leis, ou tutelando o ritual das relações sociais, manteria a sociedade presa a uma ordem praticamente imutável. Seu raciocínio é circular. Nele, as condutas estabelecidas ao longo do tempo ganham força de lei, e a lei estabelece quais são as condutas permitidas. Não é desnecessário observar nesse ponto que se ao governo por definição cabe fazer cumprir a lei, no esquema imaginado por Oakeshott, ele deverá coibir toda e qualquer conduta destoante, isto é, o conservadorismo laissez-faire de Oakeshott condena o uso do governo para promover mudanças, mas não se ressente em usá-lo como aparelho de repressão na conservação do status quo.

Em suma, Oakeshott (2016) retira o conservadorismo da esfera pública para defini-lo como uma disposição pessoal; um tipo de conduta considerada adequada, se não inofensiva, para tratar de coisas privadas 
como a amizade, afeição e familiaridade. É por conta desse movimento teórico que a expressão conservador nos costumes ganha muito da sua força. Entretanto, quando aquela disposição conservadora é imposta às coisas públicas, a política deixa de ser a instituidora do novo, como a modernidade aprendeu com Maquiavel, e adquire contornos de um regime opressivo, no qual todo tipo de conduta inovadora ou de comportamento que se desvie do tradicional tende a ser legalmente proscrito.

É preciso destacar, ainda, que o receio diante da mudança que aflige a alma do conservador não se refere apenas às coisas novas que surgem no interior de seu próprio grupo ou de sua comunidade. As novidades frequentemente têm origem fora e são importadas, ou são produzidas a partir do contato com os outros; e isso desperta no conservador uma intolerância indiscriminada aos migrantes e aversão a tudo que tenha origem estrangeira, dando origem à xenofobia, que, em seu discurso, aparece tingida de patriotismo. Por isso, todo conservador é também um patriota.

\section{Hayek: Por que não sou conservador}

Não à toa, no ensaio Por que não sou conservador 5 , Hayek (2006, p. 509) faz do "medo da mudança" a "primeira grande diferença" que separa liberais e conservadores. Para o patriarca do neoliberalismo, "o medo do novo simplesmente por ser novo" é o comportamento típico dos conservadores, enquanto o liberal é atraído "por tudo o que seja transformação e evolução" (HAYEK, 2006, p. 509, tradução nossa). Segundo Hayek (2006, p. 510, tradução nossa), os conservadores "quando olham para o futuro, não imaginam que possa haver forças desconhecidas que espontaneamente ajustem as coisas" e quando governam "tendem a paralisar a evolução". Em suma, o medo da mudança e a falta de imaginação fazem do conservadorismo uma "atitude mental" oposta à filosofia dos liberais.

Na avaliação de Hayek (2006, p. 510, tradução nossa), como o conservador desconfia de teorias abstratas e não crê em princípios gerais, não pode compreender como funcionam "as forças espontâneas que constituem o fundamento da liberdade" e não consegue "traçar diretrizes políticas" capazes de assegurá-las. Desse modo, para o conservador, a ordem sempre será fruto da vigilância exercida por autoridades que, para cumprir essa tarefa, "devem dispor dos mais amplos poderes discricionários". Já o pensamento liberal faz com que a pessoa tenha confiança de que, "graças às forças autorreguladoras do mercado", as coisas tendem a se acomodar "espontaneamente", mesmo que ninguém possa prever com detalhes como isso vai acontecer. (HAYEK, 2006, p. 510, tradução nossa)

Segundo Hayek (2006), ainda que os conservadores tenham realizado excelentes estudos sobre o desenvolvimento espontânea de instituições como a linguagem, o direito e a moral, importantes para se compreender o que é uma sociedade livre, eles foram incapazes de elaborar "uma teoria geral da sociedade e, sobretudo, do mundo econômico" (HAYEK, 2006, p. 511, tradução nossa). Consequentemente, conclui ele, por serem "carentes de princípios", os conservadores são "essencialmente oportunistas", pois não se opõem à coerção estatal quando os governantes perseguem objetivos que eles consideram corretos; e a teoria política conservadora se limita a recomendar que se coloque "pessoas boas e sábias" nos governos. (HAYEK, 2006, p. 511, tradução nossa).

Se os conservadores entendem que existem pessoas que devem ter um maior peso na condução dos negócios públicos porque são moral e/ou intelectualmente superiores, os liberais, segundo Hayek (2006), não negam a existência de pessoas superiores, nem desconhecem a importância da atuação de elites em diferentes áreas da sociedade moderna, "porém acreditam que aquele que pretende ocupar uma posição superior deve demonstrar sua superioridade acatando as mesmas regras que os demais" (HAYEK, p. 513, tradução nossa).

É preciso observar, nesse ponto, que a meritocracia advogada por Hayek consagra a competição como método de seleção da elite governante em detrimento dos tradicionais critérios plutocráticos, mas não faz dele um defensor da democracia. Hayek (2006, pp. 143-5, 513) pensa a democracia como um meio e não como um fim. Tal como propôs Schumpeter (1961), Hayek entende a democracia como um método de seleção de dirigentes; um procedimento que pode apresentar algumas vantagens em comparação a outros, mas não têm nenhum valor intrínseco; pode ser útil em algumas circunstâncias e em outras não.

É a partir dessa posição que Hayek avalia que os conservadores são ingênuos ao prescreverem um governo de pessoas boas e sábias. Para ele, a perspectiva liberal indica que o problema não está em quem exerce o poder, mas em como ele é exercido, pois, independentemente do método de escolha, "ninguém tem capacidade para exercer sabiamente poderes ilimitados" (HAYEK, 2006, p. 513, tradução nossa) e, por isso, o liberalismo se notabilizou historicamente pela luta contra os governos absolutos. Todavia, em sua avaliação, apenas "quando o poder foi transferido integralmente para as massas majoritárias" (HAYEK, 2006, p. 513, tradução nossa), perdeu-se o interesse em reivindicar a limitação dos poderes estatais. 
Na teoria política de Hayek (2006), não é inequívoco que a expansão da democracia represente um ganho em toda e qualquer circunstância. Em outra passagem nos Fundamentos da Liberdade, o autor argumenta que existem dois caminhos por onde é possível ampliar a democracia, aumentando o núcleo de pessoas que têm direito ao voto e ampliando o alcance das questões possíveis de serem decididas pelo procedimento democrático, e conclui que "em nenhum dos dois casos se pode sustentar seriamente que cada grau de expansão implica um ganho, ou que o princípio democrático exija que a extensão se prolongue de modo indefinido" (HAYEK, 2006, p. 143-144, tradução nossa).

Segundo Hayek (2006), problemas como a delimitação do escopo da deliberação democrática, ou a expansão do direito de voto, não podem ser resolvidos recorrendo-se à vontade da maioria. De acordo com ele, problemas desse tipo requerem um acordo sobre um conjunto de princípios comuns que possa funcionar como referência para a atuação do poder político. Não importa se tais princípios remetam à lei da natureza ou ao contrato social, o importante para Hayek (2006, p. 146, tradução nossa) é que "a aceitação de princípios comuns é o que faz com que um grupo de homens se converta em uma coletividade" e, portanto, são tais princípios que devem operar como parâmetro de legitimidade das decisões coletivas e não o fato de corresponderem, ou não, à vontade de alguma maioria fortuita.

No caso das sociedades políticas ocidentais, segundo Hayek, tais princípios são aqueles defendidos pelos antigos whigs, que estavam presentes na Revolução Gloriosa na Inglaterra de 1688; inspiraram os fundadores dos EUA; e "foram cristalizados naquele movimento que em toda a Europa ficou conhecido como liberal" (HAYEK, 2006, p. 519, tradução nossa). Em especial, "a ideia de uma lei suprema, que se acha acima dos nossos ordenamentos e códigos", que embasa a "tradição anglo-saxônica" e, segundo Hayek (2006, p. 520, tradução nossa), proporciona ao "liberalismo continental" aquilo que "ele tem de melhor". De acordo com Hayek, aquele movimento deixou de se denominar whig para adotar o qualificativo de liberal, "precisamente quando foi infectado pelo racionalismo rude e ditatorial da Revolução Francesa", e teve sua "fillosofia original" transmutada por seu "impulso demagógico, totalitário e socializante" (HAYEK, 2006, p. 519-520, tradução nossa).

A distinção feita por Hayek entre a tradição whig "anglo-saxônica" e um liberalismo continental corresponde à divisão no movimento que se consumou, como foi didaticamente demonstrado por Bobbio (1994, p. 52), entre um liberalismo radical, "ao mesmo tempo liberal e democrático", e um liberalismo conservador, "liberal mas não democrático", que ao longo do século XIX se manteve sempre "contra qualquer proposta de alargamento do direito de voto". Os liberais radicais, ensina Bobbio (1994), viam no regime democrático a melhor forma de realizar plenamente os ideais do liberalismo e a existência de um Estado liberal como uma condição prévia para a realização da democracia; enquanto os liberais conservadores acreditavam que a expansão da democracia levaria à destruição do Estado liberal ${ }^{6}$.

O alerta de Hayek sobre o avanço da democracia já havia sido enunciado anos antes em $O$ Caminho da Servidão, publicado originalmente na Inglaterra em 1944, e é retomado em Fundamentos da Liberdade, com pouquíssimas alterações. Antes, o tom do discurso era dado pelo debate em torno do planejamento econômico como atividade governamental, agora, a premência era dada pela ampliação do Estado de Bem-Estar ocorrida após a segunda guerra, as políticas sociais, assistenciais e previdenciárias e a distribuição de renda implícitas nelas.

De início, diz Hayek (2006, p. 350, tradução nossa), “[...] o perigo consiste em que, tão logo uma meta de governo é aceita como legítima, se presume que até mesmo meios contrários aos princípios da liberdade podem ser empregados legitimamente com esse fim". A ameaça, porém, tende a ser cada vez maior porque cada intervenção produz efeitos não previstos que levam a outras intervenções, o que faz com que o Estado demande novos poderes em uma espiral crescente. Daí a necessidade premente de limitar a ação do Estado, mesmo que isso seja feito em detrimento da vontade da maioria.

De um ponto de vista histórico, a ameaça vislumbrada por Hayek (1990, 2006), corresponde ao que Marshall (1967) havia identificado como a contraface da ampliação dos direitos na estruturação burocrática do Estado moderno. Conforme Marshall (1967) observou, a cada conjunto de direitos reconhecidos corresponde um conjunto de instituições - aos direitos civis, o sistema judiciário; aos direitos políticos, o parlamento e o sistema eleitoral; e aos direitos sociais, os sistemas, educacional, previdenciário, sanitário etc. - que constituem a estrutura do Estado moderno.

A espiral é crescente em Marshall, não porque o Estado demanda cada vez mais poderes, como afirma Hayek (2006), mas porque a cidadania não possui um contorno final preestabelecido e a cada geração demanda novos direitos. Desse ponto de vista, quando se diz que a teoria política de Hayek é antidemocrática, isso quer dizer ela não apenas conduz a retrocessos no campo político-eleitoral, mas implica também no desmonte da estrutura governamental que corresponde aos direitos socais e, em última instância, que se trata de uma teoria que nega ao cidadão o direito de ter direitos. 
Concluindo seu ensaio, Hayek (2006, p. 522) afirma que a grande tarefa que se coloca para os liberais é, "como no alvorecer do século XIX", superar "os obstáculos e impedimentos, arbitrados pela insensatez da mente humana, que interrompem e retardam o desenvolvimento espontâneo". Identificando tais obstáculos, obviamente, como os direitos políticos e sociais que desde então foram agregados à noção de cidadania. Todavia, Hayek não efetua sua conclusão sem antes lembrar que, na "oposição ao coletivismo" que une liberais e conservadores, não se deve esquecer que o liberal "olha sempre para frente, para o futuro e não sente saudades, nem deseja reviver o passado" (HAYEK, 2006, p. 521-522).

O leitor deve observar que o desenvolvimento espontâneo que Hayek (2006) quer liberar é tão somente o desenvolvimento da economia capitalista. O economista laureado se volta para o passado na esfera política, tomando os velhos whigs como referência e propondo o restabelecimento de regimes semelhantes ao que vigorava na Inglaterra no início do século XIX, olhando para o futuro na esfera econômica. O liberalismo de Hayek, portanto, define-se como um governo limitado que, de um lado, é uma condição necessária para o desenvolvimento espontâneo do capitalismo e, de outro, tem a supressão da democracia como condição para a sua existência. Dessa perspectiva, a expressão liberal na economia não tem sentido lógico, pois para produzir efeitos na esfera econômica a teoria liberal determina a limitação do poder político e se justifica apenas como uma tentativa de ocultar o caráter antidemocrático do liberalismo.

\section{Conservador nos costumes, liberal na economia e antidemocrático na política}

A essa altura, é possível avançar algumas considerações sobre o que torna possível a atual aliança entre liberais e conservadores, apesar do antagonismo verificado entre as duas correntes de pensamento.

A ideia básica que impulsiona o pensamento de Hayek é a de que como o Estado é um mal necessário, quanto menor for o seu âmbito de ação, mais fácil será o controle que se poderá exercer sobre ele. O problema é que ainda que esta seja uma noção presente na obra de inúmeros liberais desde Locke, nenhuma teoria avança no sentido de determinar qual é exatamente o âmbito mínimo, ou o máximo, aceitável para as ações do governo. O mais longe que a teoria liberal vai nessa direção é sustentar que o Estado deve ter sua ação circunscrita à esfera pública e que sua transposição para a esfera privada deve se dar apenas quando necessária para proteger a vida, a liberdade e a propriedade dos cidadãos. Contudo, também nessa formulação, a linha que separa a esfera pública da privada não é definida com precisão.

É evidente que isso se deve ao fato de que se está diante de um limite impossível de ser estabelecido aprioristicamente. Trata-se de algo que deve ser convencionado; o seu traçado expressa sempre um acordo possível em um dado momento e se altera ao longo do tempo, refletindo as transformações socioeconômicas e culturais vividas pela comunidade. Hayek, porém, faz do governo limitado a pedra de toque da sua teoria política, mas se recusa a aceitar que a tarefa de delimitá-lo fique a cargo da maioria e, na falta de um critério teórico capaz de fundamentar uma delimitação, toma arbitrariamente como referência o formato original do Estado liberal do alvorecer do século XIX, classificando toda alteração sofrida desde então como medidas autoritárias impostas pelas massas majoritárias.

Os conservadores, por sua vez, não encontram a mesma dificuldade para estabelecer os limites do governo. Segundo Burke, em assuntos da política não se pode confiar na razão individual, que é sempre limitada e parcial, devendo-se recorrer à experiência acumulada pelas gerações ao longo da história. Na teoria conservadora, portanto, o governo encontra um limite na tradição; em práticas instituídas e consagradas pelo tempo e não baseadas em abstrações filosóficas e facilmente alteradas por pactos e convenções. A teoria de Burke, entretanto, remete a um princípio de legitimidade distinto daquele adotado pelo liberalismo.

Enquanto a formulação conservadora encontra na prescrição sua fonte de legitimidade, todo edifício institucional desenvolvido sob influência liberal está firmemente apoiado na convicção de que o cidadão é um sujeito racional, que deve ser livre para decidir individualmente o seu futuro e participar das decisões sobre o futuro da coletividade, e encontra no consentimento do cidadão a sua fonte de legitimidade. Por isso é um problema para Hayek estabelecer, de modo legítimo, o limite que circunscreve as ações do Estado, e esse problema não ocorre aos conservadores. Não apenas porque eles são oportunistas, como quer Hayek, mas porque ao seu lado sempre haverá exegetas dispostos a oferecer a correta interpretação dos ensinamentos da tradição ${ }^{7}$. Hayek (2006), porém, vê-se obrigado a um esforço teórico maior. Para equacionar o problema, ele precisa recorrer ao conceito de massa.

De acordo com a sociologia conservadora do século XIX, indivíduos racionais quando agem em conjunto com outros na forma de multidão, de uma massa que obscurece a identidade e arrefece os freios morais do indivíduo, apresentam um comportamento irracional. É nessa teoria que Hayek (2006) encontra justificativa para propor a restrição do poder político das massas e a restauração de um Estado senhorial lockeano como a 
Inglaterra do alvorecer do século XIX - mesmo que isso signifique, na prática, alijar a maioria da população do processo político, juntamente com as instituições historicamente ligadas a ela, como os partidos de massa, os sindicatos e os movimentos sociais.

Por caminhos diferentes, portanto, as duas correntes de pensamento conduzem a um mesmo ponto: muito além da retórica anticomunista comum a conservadores e liberais, e que não à toa persiste mesmo após a queda do Muro de Berlim, a desintegração da União Soviética e a conversão do regime chinês ao capitalismo, o que se destaca na propalada expressão conservador nos costumes e liberal na economia é que por ambos os termos ela remete a uma vigorosa negação da democracia.

Para evitar possíveis mal-entendidos, é preciso ressaltar que a democracia contra a qual se levantam liberais e conservadores não é aquela reduzida a simples método de escolha da elite dirigente, consagrada pela teoria schumpeteriana da democracia. Hayek (2006) aceita que o método da maioria seja adequado a determinadas circunstâncias, mas não acredita que a democracia possua algum valor em si que a torne desejável em qualquer circunstância. Note-se que não é contraditório o apoio que o patriarca do neoliberalismo deu à ditadura do general Pinochet no Chile. Reduzida a um simples procedimento, um método isento de qualquer valor intrínseco, a democracia pode ser facilmente descartada quando se considerar conveniente.

O que Hayek (2006) recusa é o conteúdo substantivo da democracia que aponta para a igualdade. A teoria de Hayek se sustenta no antigo dilema tocqueviliano da oposição entre liberdade e igualdade, acompanhando o nobre francês na convicção de que o povo tende a priorizar a segunda em detrimento da primeira, fazendo com que a democracia resulte em uma tirania da maioria. Porém, enquanto o barão de Tocqueville (1998) enxergava a igualdade como a variável incontrolável, resultante do processo histórico que conduzia a ascensão da burguesia, e voltava suas preocupações para a proteção institucional da liberdade, Hayek (2006) presenciava a igualdade resultante das políticas distributivas impostas pela força das massas no processo democrático e postulava a manutenção da liberdade a partir da limitação do seu poder.

Para os conservadores também a desigualdade é um produto natural do processo de trocas e interações sociais e que não pode ser anulada pelo cálculo intervencionista do governo da maioria. E ao tentar fazê-lo, o governo das massas faz tábula rasa dos costumes e da tradição de modo que suas ações serão consideradas sempre autoritárias.

No fim, tanto o liberalismo de Hayek quanto o conservadorismo de Burke entendem que toda política que encontra na igualdade uma referência moral é um atentado contra a liberdade. Se perguntassem liberdade de quem, provavelmente concluíssem, com Oakeshott, que se trata da liberdade daquela parcela da sociedade que apresenta maior disposição conservadora porque é constituída pelos que aprenderam a amar o que têm; em detrimento daqueles que nada têm, mas - talvez por isso mesmo - aprenderam a amar a liberdade e ambicionam ser livres também.

\section{Referências}

BOBBIO, N.; MATTEUCCI, N.; PASQUINO, G. Dicionário de política. 4. ed. Brasília: Editora Universidade de Brasília, 1992. BOBBIO, N. Liberalismo e Democracia. 6. ed. São Paulo: Editora Brasiliense, 1994.

BURKE, E. Reflexões sobre a revolução em França. Brasília: Editora Universidade de Brasília, 1982.

FRASER, N. Mapeando a imaginação feminista: da redistribuição ao reconhecimento e à representação. Estudos Feministas, Florianópolis, v. 15, n. 2, p. 291-308, maio/ago. 2007.

HAYEK, F. A. O Caminho da Servidão. 5. ed. Rio de Janeiro: Instituto Liberal, 1990.

HAYEK, F. A. Los Fundamentos de la Libertad. 7. ed. Madrid, España: Unión Editorial, 2006.

HIRSCHMAN, A. O. A Retórica da Intransigência: perversidade, futilidade, ameaça. São Paulo: Companhia das Letras, 1992.

MAISTRE, J. de. Consideraciones sobre Francia. Madrid: Editorial Tecnos, 1990.

MARSHALL, T. S. Cidadania, Classe Social e Status. Rio de Janeiro: Zahar, 1967.

MARX, K. A Questão Judaica. São Paulo: Editora Moraes, 1991.

NISBET, R. O Conservadorismo. Lisboa: Editorial Estampa; 1987.

OAKESHOTT, M. Ser Conservador. In: OAKESHOTT, M. Conservadorismo. Belo Horizonte: Editora Âyiné, 2016, p. 176-235. PISIER, E. História das Ideias Políticas. Barueri: Manole, 2004.

ROUSSEAU, J. J. Do Contrato Social. São Paulo: Nova Cultural, 1991. (Os Pensadores).

SCHUMPETER, J. A. Capitalismo, Socialismo e Democracia. Rio de Janeiro: Editora Fundo de Cultura, 1961.

TOCQUEVILLE, A. de. A democracia na América. 4. ed. Belo Horizonte: Itatiaia; São Paulo: Edusp, 1998.

YOUNG I. M. O ideal da imparcialidade e o público cívico. Revista Brasileira de Ciência Política, Brasília, n. 9, p. 169-203, set./dez. 2012. 


\section{Notas}

1 Ver, por exemplo, o Dicionário de Política organizado por Bobbio, Matteucci e Pasquino (1992); a consagrada História das Ideias Políticas de Evelyne Pisier (2004); ou o estimulante ensaio de Hirschman (1992) sobre a retórica reacionária.

2 Todas as citações de Burke neste tópico remetem à edição da Editora Universidade de Brasília, de 1982.

3 Adotamos aqui a tese da perversidade formulada por Hirschman (1992) em A Retórica da Intransigência para descrever esse tipo de argumento. Em síntese, nesse ensaio Hirschman sugere que uma das estratégias reacionárias diante de qualquer ação com o objetivo de alterar a ordem social, política ou econômica é argumentar que tais ações sempre provocam o efeito perverso de exacerbar a situação que se deseja remediar. Assim, no discurso reacionário, políticas redistributivas apenas tendem a gerar mais desigualdades, ou políticas emancipadoras apenas geram mais e maior dependência.

4 Todas as citações a seguir remetem à versão em português desse ensaio publicada, em 2016, pela Editora Âyiné.

5 Trata-se de um ensaio publicado originalmente como posfácio em The Constitution of Liberty, de 1959. As citações feitas nesta seção, exceto quando explicitamente indicadas, remetem à edição espanhola Los Fundamentos de la Libertad e foram traduzidas por mim para uso exclusivo neste ensaio.

6 Na passagem em referência, Bobbio (1994) sugere a existência de diferentes modelos teóricos como possibilidades em disputa na Europa ao longo do século XIX. Um modelo liberal democrático, um liberal não democrático e um democrático não liberal que permaneceu próximo do socialismo, que, por sua vez, também se dividia em socialismo democrático e não democrático.

7 Razão pela qual, aliás, dificilmente os conservadores admitem a laicidade do Estado e reservam à religião um papel de destaque nos processos políticos. Ver Burke (1982, p. 113-117).

\section{Osmir Dombrowski}

osmirdom@yahoo.com.br

Doutor em Ciência Política pela Universidade de São Paulo (USP)

Docente do Programa de Pós-graduação em Serviço Social da Universidade Estadual do Oeste do Paraná (UNIOESTE)

\section{UNIOESTE}

Rua da Faculdade, n. 645 - Jardim Santa Maria

Toledo - Paraná - Brasil

CEP: 85903-000

\section{Agradecimentos \\ Não se aplica.}

\section{Agência financiadora}

Não se aplica.

Contribuições das autoras

Não se aplica.
Aprovação por Comitê de Ética e consentimento para participação

Não se aplica.

Consentimento para publicação

Consentimento do autor.

Conflito de interesses

Não há conflito de interesses. 